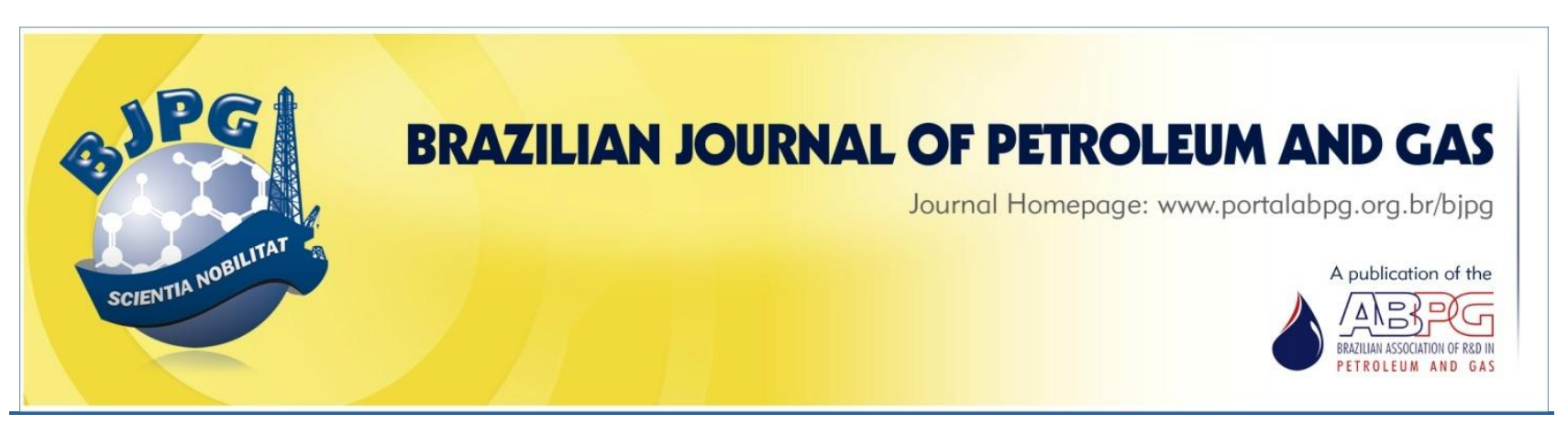

\title{
VENTURI GAS LIFT VALVE: THEORY AND PRACTICE
}

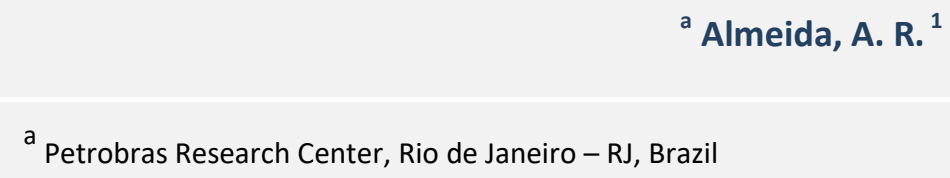

\section{ABSTRACT}

The Venturi valve represents a significant advance in the technology of artificial lift by gas lift. Understanding theoretical and practical aspects related to the use of the valve is fundamental to maximize the benefits of its application. This review article presents the concepts involved in that innovation, discusses advantages and limitations of that technology, provides means to perform gas flow rate calculations, and describes practical aspects that must be observed for a good performance of the valve.

\section{KEYWORDS}

petroleum production; artificial lift; gas lift; gas lift valve; Venturi gas lift valve

\footnotetext{
${ }^{1}$ To whom all correspondence should be addressed.

Address: PETROBRAS/CENPES/PDIEP/EE, Av. Horácio de Macedo 950, Cidade Universitária, llha do Fundão, Rio de Janeiro - RJ, Brazil

ZIP Code: 21949-900| Phone number: +55 2121624160 | e-mail: alcino@petrobras.com.br doi:10.5419/bjpg2020-0015
} 


\section{INTRODUCTION}

The use of Venturi-nozzle (or simply Venturi) gas lift valve in continuous gas lift wells is becoming frequent worldwide. Some articles (Aliyeva and Novruzaliyev, 2015; Almeida, 2010, 2011a, 2011b, and 2015; Faustinelli et al., 1999; Kartoatmodjo et al., 2008; Lyngholm et al., 2007; Motta et al., 2005; Nwadike et al., 2014; Rilian et al., 2012; Tokar et al., 1996) focus on describing different aspects of that technology. In Brazil, according Almeida (2015), more than 350 offshore wells were equipped with these valves and Petrobras, alone, had either run in wells or experimentally tested more than 600 valves with Venturi. with Venturi geometry may be used ${ }^{2}$.

In subsea wells there is a tendency to adopt single point injection, and Venturi valves have been preferred not only because of its flow characteristics but also because its external check valve has proved to be more robust in comparison with the internal check valve usually present in orifice valves. In the latter case, the dart legs often break, turning the dart upside down and blocking the gas passage (working as a check valve in the wrong direction). For wells with high gas injection rate this phenomenon may happen in a relatively short period of time, causing a premature intervention which is very costly in subsea wells (accompanied by a significant production loss in case of a shortage of rigs).

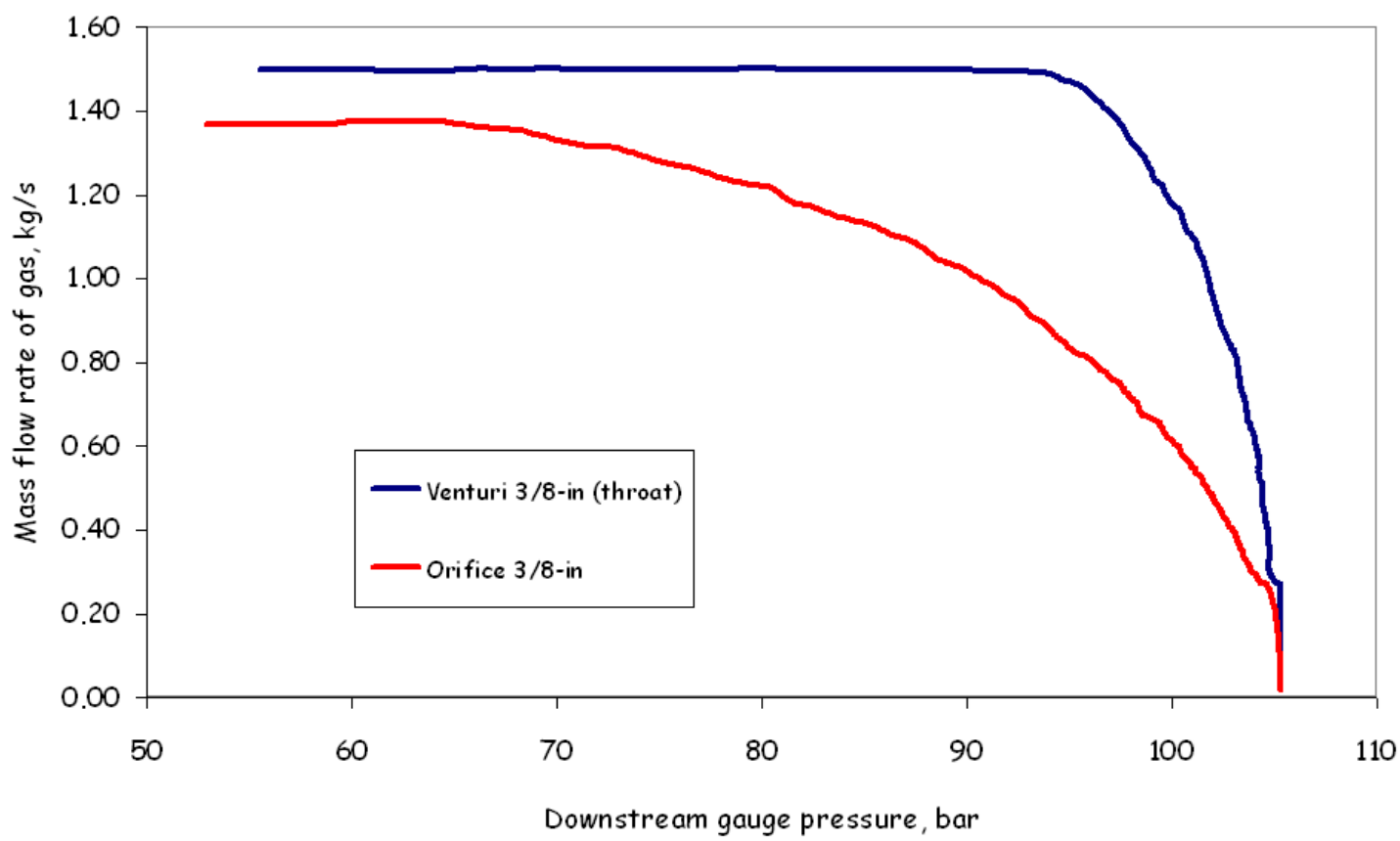

Figure 1. Dynamic performance comparison between two commercial 1.5-in OD gas lift valves, one with a Venturi and the other with an orifice plate. Curves obtained at Petrobras' Gas Lift Valves Test Unit in Aracaju, Brazil, with natural gas and 105 bar upstream gauge pressure.

Roughly speaking, there are two types of gas lift valves. One has a mechanism to open or close the valve according to pressure (and, in most cases, temperature) conditions in the well. Charged bellows is the most usual mechanism of this type of lift valve. The other one involves valves that are always open (in the casing to tubing direction). In general, there are just a choke to restrict flow rate and a check valve to avoid reverse flow from tubing to casing. The most used choke is a cylindrical plate with a square edge orifice. Alternatively, a choke
Figure 1 presents experimental gas flow curves, comparing a Venturi valve with a conventional square edge orifice valve. The difference in terms of critical flow is clear, i.e., the region of the curve where the gas flow rate through the valve is constant, irrespective of downstream pressure. Critical flow occurs when downstream pressure is less than a certain fraction of the upstream pressure. This fraction, called critical ratio, is

\footnotetext{
${ }^{2}$ In part, this review article makes use of some excerpts from Almeida (2010, 2011a, 2011b, and 2015).
} 


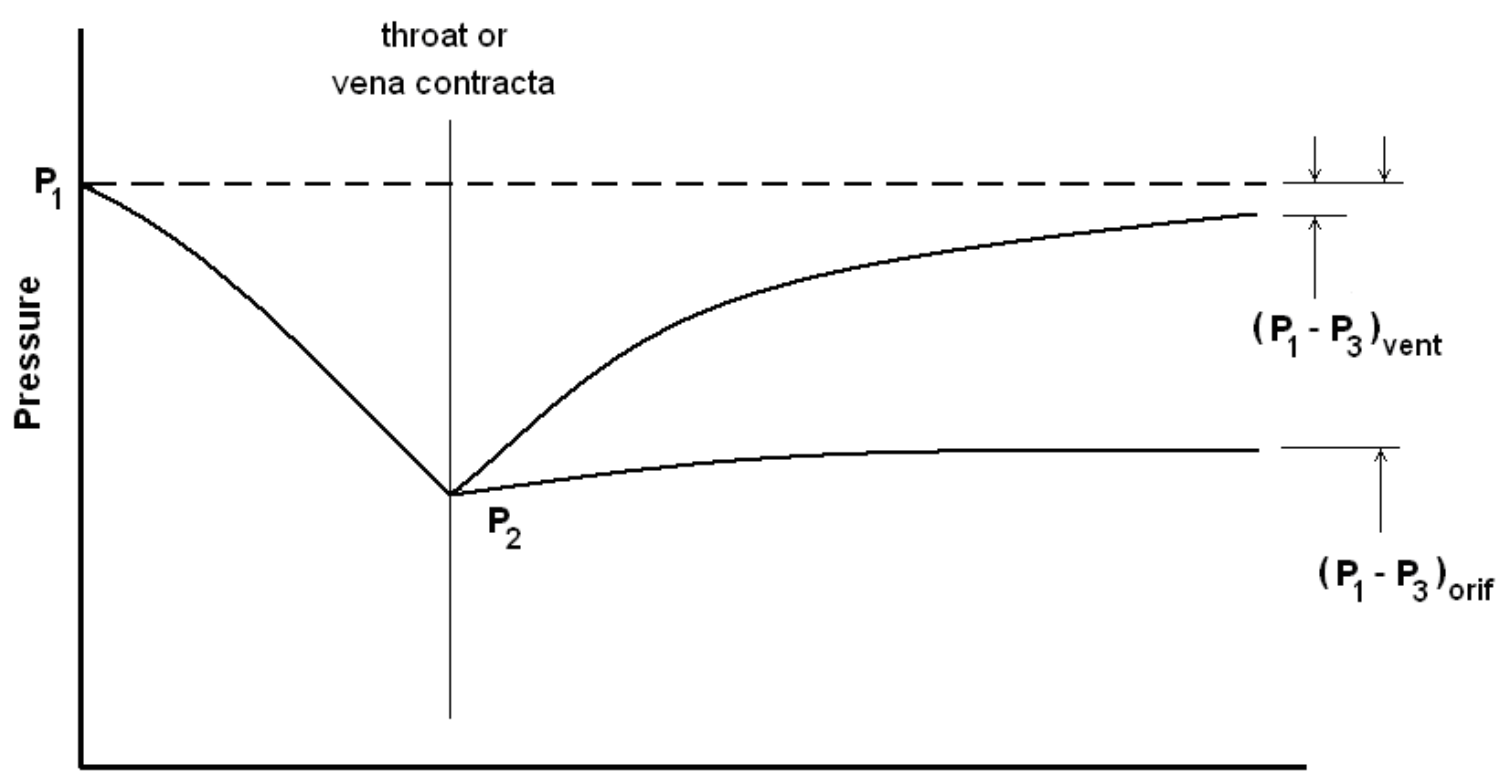

Distance from the inlet plane

Figure 2. Pressure profiles along the gas path through a Venturi and an orifice valve.

roughly 0.5 for an orifice valve and 0.9 for a Venturi valve. Thus, in view of the usual pressure differentials between casing (injection pressure) and tubing (production pressure), orifice valves operate under subcritical flow regime and Venturi valves under critical flow.

Figure 2 presents a schematic comparison between pressure profiles for both, Venturi and orifice valves in the case of subcritical flow. The pressure decreases from $P_{1}$ to $P_{2}$, where $P_{1}$ is the injection pressure in the casing (neglecting pressure drop at inlet ports of the mandrel and of the valve itself) and $P_{2}$ is the pressure at the main flow restriction (orifice vena contracta or Venturi throat). The behavior upstream the restriction is similar in both situations (disregarding some effects resulting from the abrupt contraction upstream the square edge orifice). Downstream, however, the Venturi diffuser promotes a great pressure recovery from $P_{2}$ to $P_{3}$, which represents the production pressure in the tubing (neglecting pressure drop at outlet ports and at the check valve). In turn, such recovery is very small for the orifice.

Hence, to reach the same pressure $P_{2}$ at the main flow restriction, a much lower pressure $P_{3}$ will be required using an orifice instead of a Venturi. Conversely, for the same pressure $P_{3}$, the corresponding pressure $P_{2}$ is considerably lower in the Venturi if compared to that in the orifice choke. If the throat and orifice areas are the same, it means that, for the same tubing pressure $P_{3}$, gas flow rate is greater for the Venturi than for the orifice.

If tubing pressure $P_{3}$ is reduced steadily, eventually, the critical flow will be established and pressure $P_{2}$ will assume its critical value $P_{2 c}$. At this point, the corresponding tubing pressure is the critical tubing pressure $P_{3 c}$. As previously discussed, $P_{3 c}$ is much greater for the Venturi due to the remarkable pressure recovery at the diffuser.

Additional tubing pressure reductions will not affect conditions at the main restriction and gas flow rate will remain constant. Pressure profiles downstream the restriction will be different from those of Figure 2, with a shock wave occurring at some position. Nevertheless, this analysis is not relevant to our present discussion. The key point is that the difference in terms of pressure recovery downstream the main flow restriction is responsible for the different shapes of performance curves between Venturi and orifice valves, as shown in Figure 1.

Observing Figure 1, another important difference is the lower critical gas flow rate for the orifice when compared with a Venturi with the same throat diameter and submitted to the same 

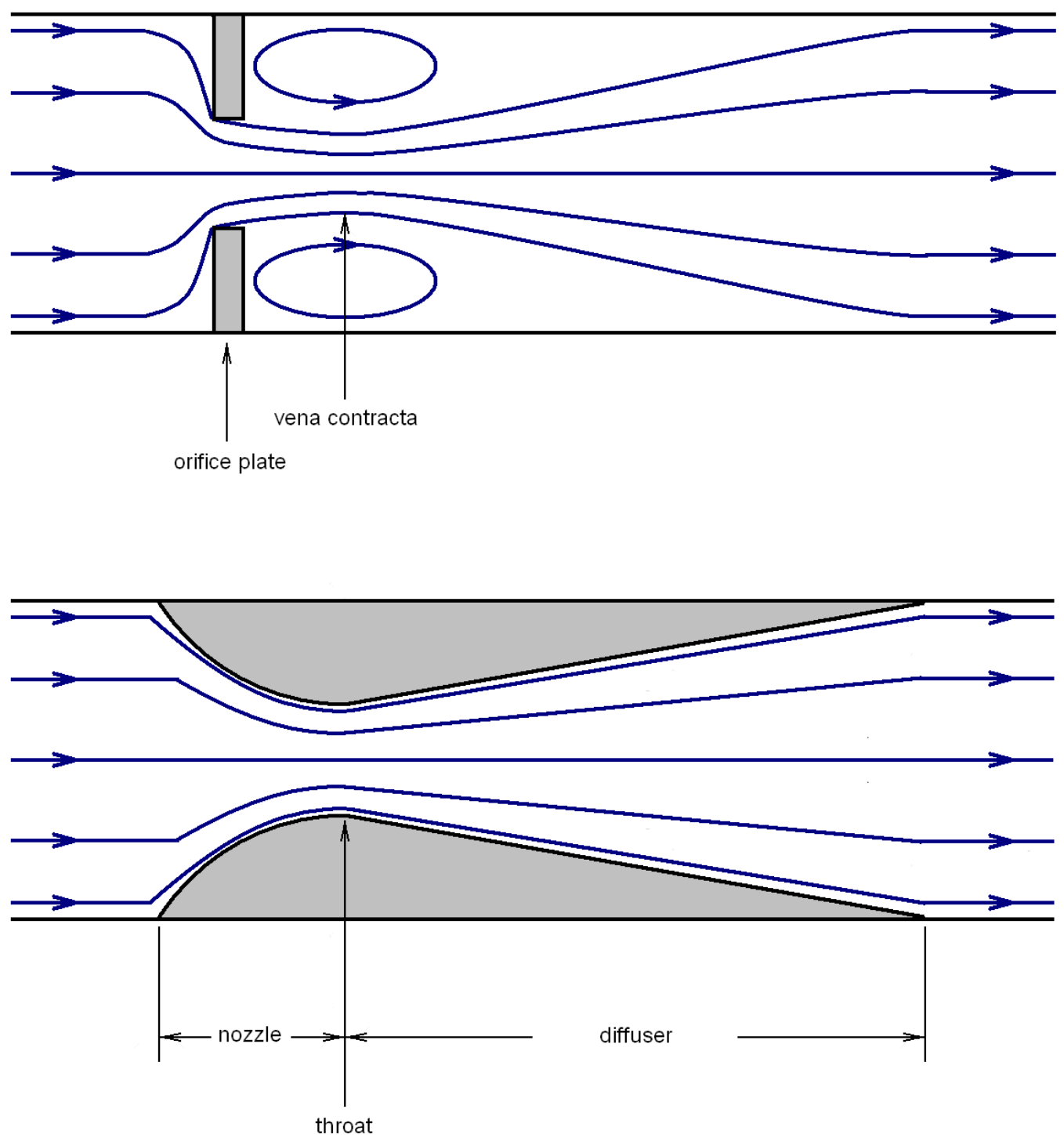

Figure 3. Schematic streamlines for gas subcritical flow through an orifice (showing the vena contracta) and a Venturi. In critical flow, a shock wave will appear somewhere downstream the vena contracta or throat but streamlines upstream will present the same comparative behavior.

upstream conditions and flowing the same gas. The main reason for that is the presence of a vena contracta downstream the orifice. It is originated by swirling eddies formed after the sudden expansion. Figure 3 shows that the main jet from the orifice is then contracted forming the vena contracta, which is the smallest flow area. In a Venturi, the smallest flow area is the throat area itself.

Since most advantages of a Venturi valve come from the high critical ratio, which depends on valve design, we define a valve as being a Venturi valve if the critical ratio is 0.9 or greater, considering the gas and pressure-temperature conditions of the actual application. Valves with lower critical ratios are not considered Venturi but may still be used depending on the specific case. The decision to whether or not to use a specific type of valve will be made by a gas lift designer with that information at hand. Moreover, critical ratio may be now considered as a design parameter among others, since intermediate values may be obtained by truncating the diffuser, for example.

In theory, Venturi valves may be used in all wells producing by (continuous) gas lift. In practice, some factors may prevail and orifice valves may be 
recommended instead. Thus, it is important to know the advantages and limitations of Venturi valves if compared to orifice ones.

\section{CONTROLLING UNSTABLE FLOW}

In a gas lift well, severe flow instabilities may occur and, beyond certain limit, they can cause shutdown in process plants and other operational problems. Moreover, unstable wells may preclude automatic field optimization schemes to work properly and may have to be excluded of the scheme, losing potential benefits. Methods to control such instabilities generally result in production losses and, sometimes, higher operational costs.

Those gas lift instabilities are caused basically by three mechanisms, the most usual being casing heading. In this case, gas flow through operating gas lift valve is subcritical and disturbances in production pressure cause changes in gas flow rate through the valve. Thus, the gas flow dynamics in the casing-tubing annular becomes linked with tubing flow dynamics. Under certain conditions, these variations in flow rates and pressures are amplified and perpetuated, resulting in an unstable well flow. Depending on the configuration of the system, other wells may be affected producing a domino effect.

Even before Venturi valves were available in the market, gas lift valves, operating under critical flow, were recognized as a possible solution to avoid casing-heading instability, since, in this case, gas injection flow rate is not affected by fluctuations in tubing pressure (Alhanati et al., 1993; Grupping et al., 1984; Moore and Adair, 1991). However, the abovementioned solution was not considered practical or economical due to the large pressure differential between casing and tubing required to achieve critical flow through orifice valves. In contrast, such pressure differential is relatively small for Venturi valves. Thus, it is natural, and has been verified in practice, that one of the most important advantages of Venturi valves is to prevent flow instabilities caused by casingheading (Faustinelli et al., 1999; Kartoatmodjo et al., 2008; Nwadike et al., 2014; Tokar et al., 1996).

A second instability mechanism is density wave (Hu and Golan, 2003). It can occur even with critical flow through the gas lift valve, i.e., it occurs despite of a constant gas injection flow rate. Variations in reservoir fluid intake to the well cause variations in the density of the produced fluid. That disturbance propagates through the tubing as a "density wave." In theory, the system will selfregulate, because an increase in liquid flow rate would increase the fluid density inside tubing and, in turn, it would result in higher formation backpressure. Hence, it would lead to a reduction in the liquid flow and, therefore, a decrease in fluid density (considering gas injection rate constant through the gas lift valve). Similar stabilization process would occur in the event of a reduction in the liquid flow. However, this natural process of stabilization is delayed, since cause and effect are out of phase due to the propagation time of disturbances along the well (a "density wave"). Depending on conditions, a strong cyclical instability can be established. This type of instability is associated with deep wells producing from depleted reservoirs, and the Venturi valve is unable to solve that problem ( $\mathrm{Hu}$ and Golan, 2003).

A third mechanism is related to operational problems involving equipment, particularly, gas lift valves or inadequate procedures. Some references in literature (Almeida and Slobodcicov, 1998; Hanson, 1985) report cases of unstable production caused primarily by discharge valves with mechanical issues, opening and closing repeatedly. In general, once the problematic valve is replaced, the well turns to produce steadily.

Subsea wells with flowlines on hilly terrain or descending towards the platform also represent another threat in terms of unstable flow. Severe slugging may occur under certain conditions and regardless of the gas lift valve selected. One possible solution to the issue is to increase gas injection flow rate. Venturi valves may be helpful on this, because they allow substantial increase in gas flow rate, as we will discuss next. Besides, maintenance of critical flow avoids the introduction of a new possible source of instabilities. Although not directly related to our scope, it is interesting to note that the insertion of a device with Venturi geometry inside the flowline near the riser touchdown point may eliminate severe slugging (Almeida and Gonçalves, 1999). 


\section{HIGHER GAS FLOW RATE}

As shown in Figure 1, replacing an orifice valve operating in subcritical flow with a Venturi one results in a gas flow rate increase that may be significant if the throat area is the same as the original orifice. Thus, Venturi valves generally have smaller throat areas than the corresponding orifices for the same application. For example, a $9.5 \mathrm{~mm}$ (3/8 inch) orifice operating at $200 \mathrm{bar}$ and $80{ }^{\circ} \mathrm{C}$ upstream with a 0.75 specific gravity gas and 25 bar of pressure differential across the valve could likely be replaced by a $7.0 \mathrm{~mm}$ (9/32 inch) throat diameter of Venturi.
However, in several applications, the objective is just to increase flow rate across the valve. Limitations in maximum available pressure differential may exist, reducing the maximum gas flow rate that can be reached with the given orifice valve. Such limitations may be caused by compressor constraints, uncertainties in some parameters assumed during gas lift string design, partial obstruction at some point in gas flow path, among other causes. Although orifices up to 12.7 $\mathrm{mm}(0.5 \mathrm{in})$ may be used in 1.5 -in OD valves, there is a certain fear of introducing instability, which has limited the orifice diameters that cautious designers may specify in case of relatively small pressure differentials. This belief that smaller

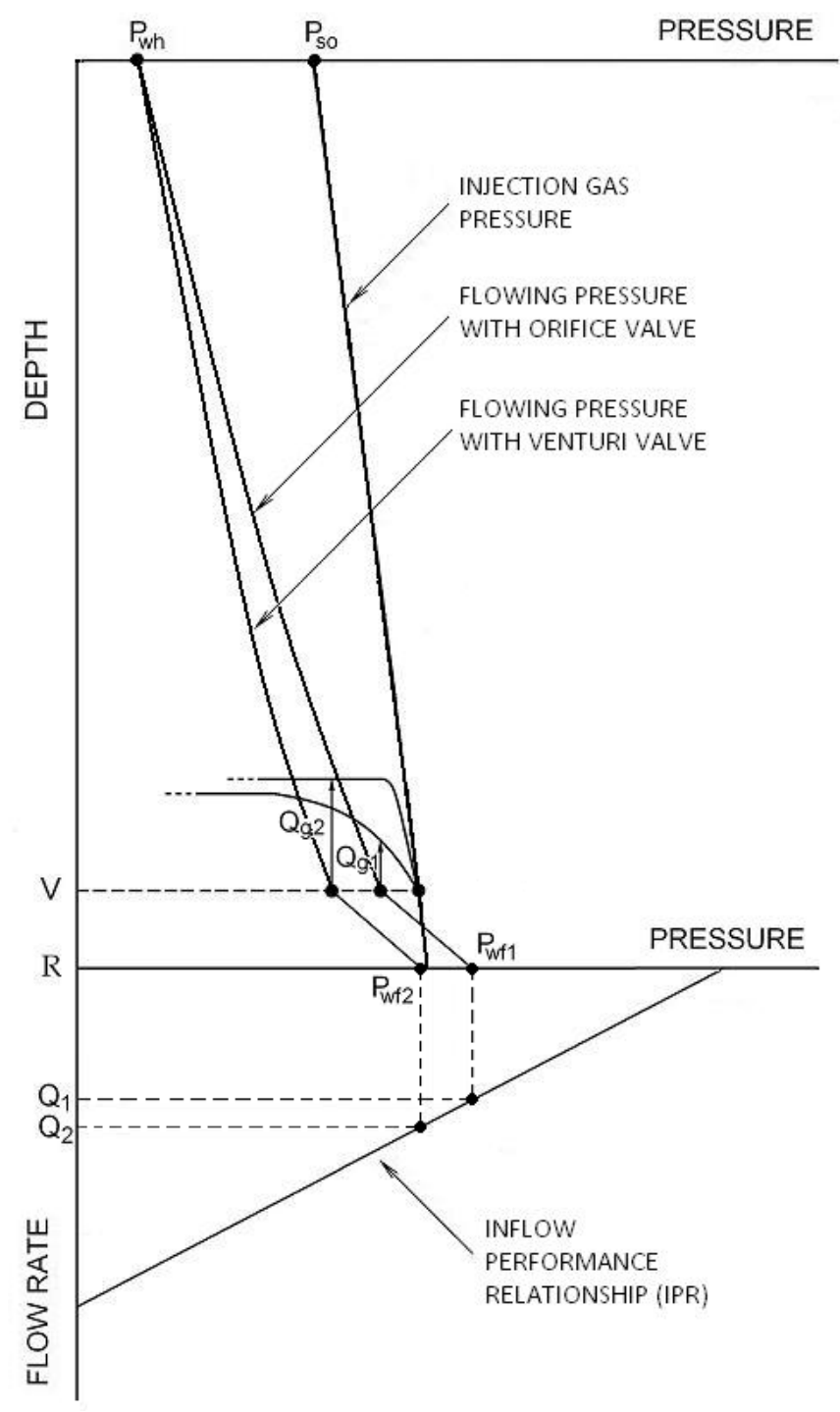

Figure 4. This illustrative graph combines pressure profiles, valve performance, and reservoir inflow to show how gas injection flow rate may be increased with a Venturi valve. With the orifice valve, the gas flow rate $Q_{g 1}$ results in a flowing pressure $P_{w f 1}$ at reservoir (R) depth, which means a liquid flow rate $Q_{1}$, according to the IPR. Replacement of the orifice valve with an appropriate Venturi valve promotes critical flow with a higher gas flow rate $Q_{g 2}$, a lower flowing pressure $P_{w f 2}$, and an increased liquid flow rate $Q_{2}$. 
orifices are conducive to stability comes from the performance curve shape. As the orifice increases, the variation in gas flow rate for a given fluctuation in tubing pressure becomes larger (smaller orifices play a better role as a "control" to disturbances in tubing pressure), see Grupping et al. (1984). Thus, to inject more gas with an orifice valve in that situation, it is necessary to inject with a greater pressure differential in a shallower depth, which probably means a rig intervention to change string and a less efficient gas lift. Replacing the orifice valve with a properly sized Venturi valve generally solves this problem effectively, as illustrated by Figure 4. Aliyeva and Novruzaliyev (2015) and Rilian et al. (2012) showed applications of Venturi valves to increase gas injection flow rate.

Conversely, because a Venturi valve requires a smaller pressure differential to inject the desired amount of gas in a stable manner, the injection point may be deeper, resulting in production increase, as schematically shown in Figure 5. Mota et al. (2005) pointed out that a sensitivity analysis is required to evaluate the gain in oil production by deepening the gas lift mandrel, considering the reservoir pressure behavior along the well lifetime and possible workovers to change the gas lift valve position.

Alternatively, if the injection point is the deepest possible, injection pressure may be

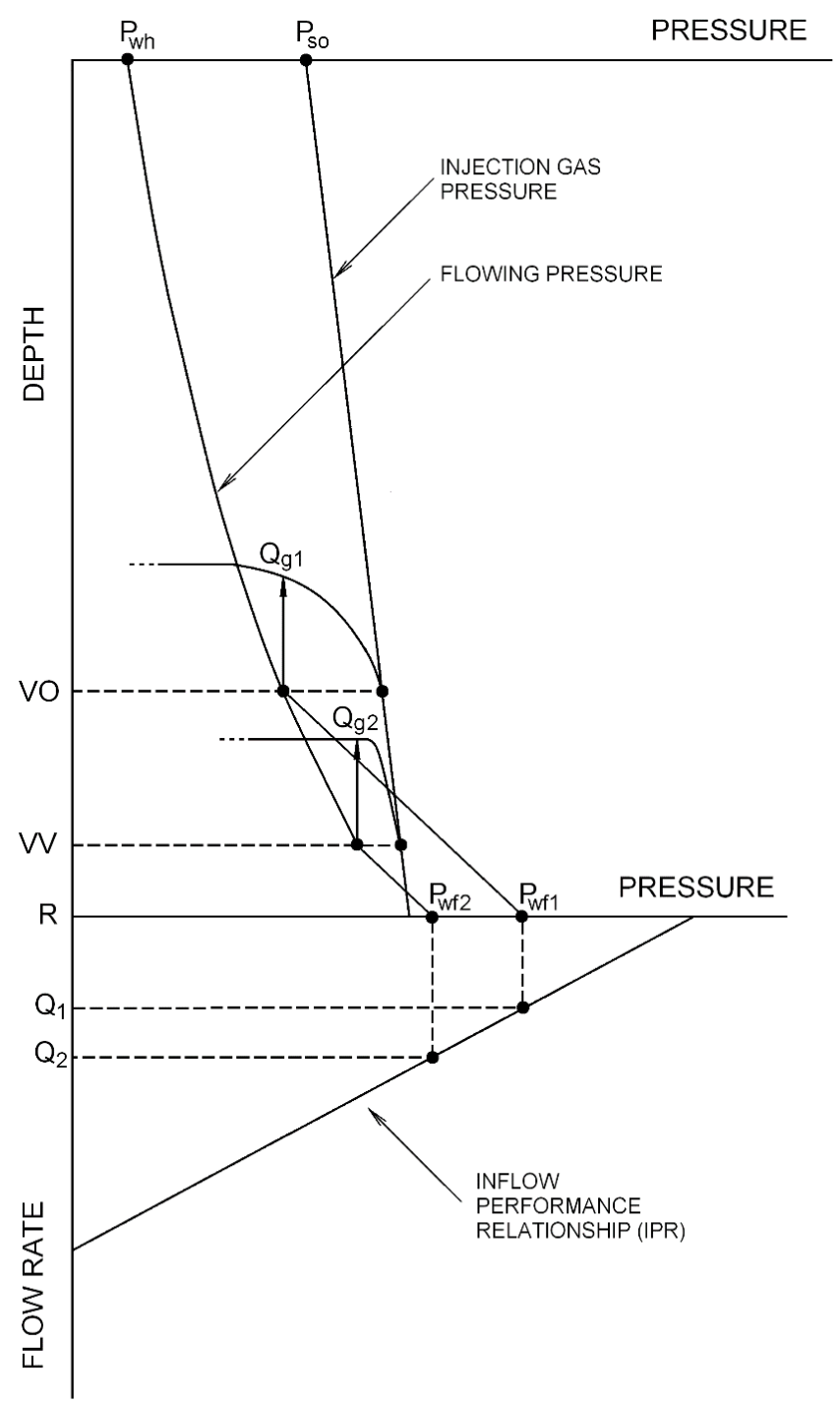

Figure 5. This illustrative graph shows how the injection point may deepen with a Venturi valve. The orifice valve (VO) is set at a depth that results in a flowing pressure $P_{w f 1}$ at reservoir (R) depth, which means a liquid flow rate $Q_{1}$, according to the IPR. Assuming that it is not possible or advisable to increase orifice size, a Venturi valve (VV) may be set at a deeper point, resulting in a reduced flow pressure $P_{w f 2}$ and an increased flow rate $Q_{2}$. This graph assumes that the tubing flowing pressure curve is the same for both cases (minimum gradient, for example). 
reduced. Reducing injection pressures may be interesting for new development projects where compressor capacity is being established, although frequently what defines the pressure level is the gas exportation not gas lift. However, there are situations in which gas is bought from external sources and there is some room for choice of pressure levels, resulting in different costs. In other situations, the gas comes from gas wells (or gas caps) and, as they deplete, cannot maintain the same pressure level previously required. Finally, if injection pressure reduction is accompanied by a reduction in the compressor suction pressure and, hence, in separation pressure, it may lead to increased flow rate from the wells.

Besides gas lift, flow assurance concerns may also recommend working with low pressuredifferentials across the valve to reduce JouleThomson cooling. Venturi valves allow injecting large amounts of gas in a stable manner and with relatively low pressure-differentials.

\section{OTHER ADVANTAGEOUS APPLICATIONS}

\subsection{Dual completions}

In oil fields with more than one producing zone, dual-completion schemes for producing two reservoirs via separate strings inside the same well is a very interesting option due to the reduction of investment required to develop the field. However, production of these wells normally presents operational problems that often reduce or eliminate potential gains. In dual completions with continuous gas lift, the Venturi valve contributes to optimization and stabilization due to the ease of reaching critical flow and, hence, constant injection gas flow rate. Disturbances that occur in one string do not affect the other string, i.e., the strings are almost isolated as if they were individual wells. Moreover, Venturi valves improve the overall system control and production monitoring. In wells with an orifice valve operating in subcritical flow, it is difficult to calculate precisely how much gas is being injected because it depends strongly on tubing pressure, which usually is only estimated and may oscillate considerably. However, generally, such lift gas flow rate may be measured directly, overcoming that problem. In dual completions, even when measuring total lift gas flow rate, the lift gas distribution between strings is difficult to estimate. As a consequence, one cannot accurately know the amount of associated gas being produced by each interval, even with individual production flowlines. With Venturi valves, the gas injection flow rate into each string is almost constant and much more predictable with a good mathematical model. If the operating valves of both strings are close in depth and the total injected gas is measured, the flow rate through each valve can be reasonable estimated dividing the total rate proportionally to the throat areas of each valve. If the valves present different depths, a small adjustment can be made using the calculation model. Kartoatmodjo et al. (2008), Nwadike et al. (2014), and Tokar et al. (1996) describe applications of Venturi valves in dual wells.

\subsection{Limiting efficiency losses}

Under special circumstances, having more than one injection point in the production string may be beneficial. One possible example is to reconcile two very different scenarios associated with changing conditions, such as reservoir pressure, water cut, and gas source. One scenario may allow injection in a deeper point in comparison with the other. Bellows charged valves may be employed, but this may not be desirable. When using orifice valves, the shallower valve is designed for the gas flow rate required when the injection is performed exclusively through it. When the injection is also occurring at the deeper point(s), the tubing pressure in front of that shallow valve is much smaller resulting in a much higher gas flow (see Figure 6 , point 1 of single injection versus point 2 with multiple injection). By employing the Venturi valve (with a smaller throat diameter to meet the required gas flow rate, see Figure 6 , point 1 ) the injection flow rate is limited, even with the reduction in tubing pressure (Figure 6 , point 1 versus point 3 ). Other cases of unexpected multiple injection (for example, failure in bellows valves that remain accidentally open) may have their effects minimized if an appropriate Venturi choke is used downstream the main valve port.

\section{LESS FLEXIBILITY}

Figure 7 illustrates one of the main reasons why the orifice valve is sometimes preferred. For a 


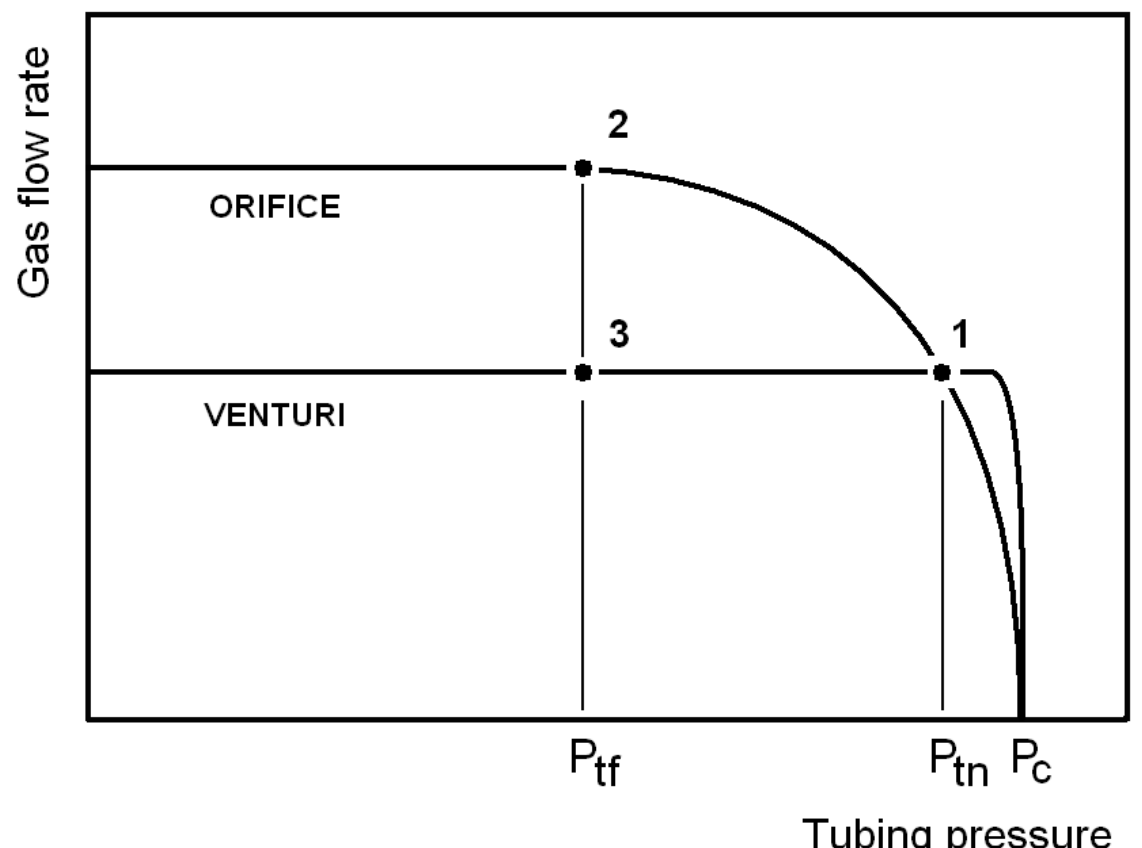

Figure 6. Venturi valves or Venturi chokes in bellows valves may limit efficiency losses in the case of two scenarios assisted by the same gas lift string.

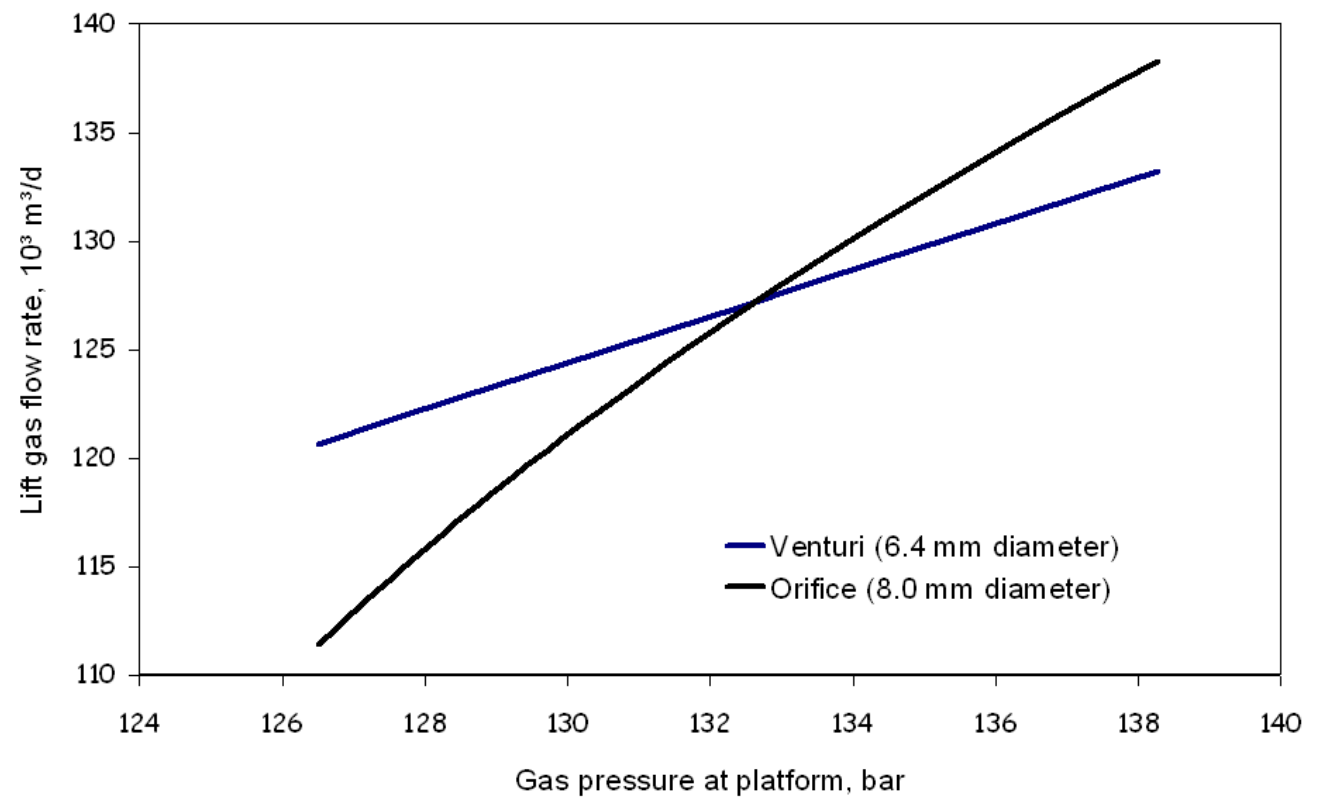

Figure 7. Comparison between orifice and Venturi valves, in terms of sensitivity to gas injection pressure, for a hypothetical subsea well (gas flow rate given in standard conditions).

hypothetical well, lift gas flow rates were calculated using Petrobras' artificial lift simulator MARLIM as a function of injection pressure at the platform (i.e., the sensitivity of gas flow rate as a function of gas injection pressure) for two situations: a valve with an $8.0 \mathrm{~mm}$ orifice and a valve with a $6.4 \mathrm{~mm}$ throat Venturi. The diameters are different because the two valves inject the same amount of gas required at the operating point (132.4 bar with $126700 \mathrm{~m}^{3} / \mathrm{d}$ of gas). It may be noted that the Venturi valve is less sensitive to casing pressure changes than the orifice valve. For the same injection pressure variation around the operating point (approximately \pm 6 bar), a variation in gas flow rate from $-12 \%$ to $+9 \%$ of the designed flow rate is obtained for the orifice valve. In the Venturi valve case, the corresponding variation is $5 \%$ to $+5 \%$. 


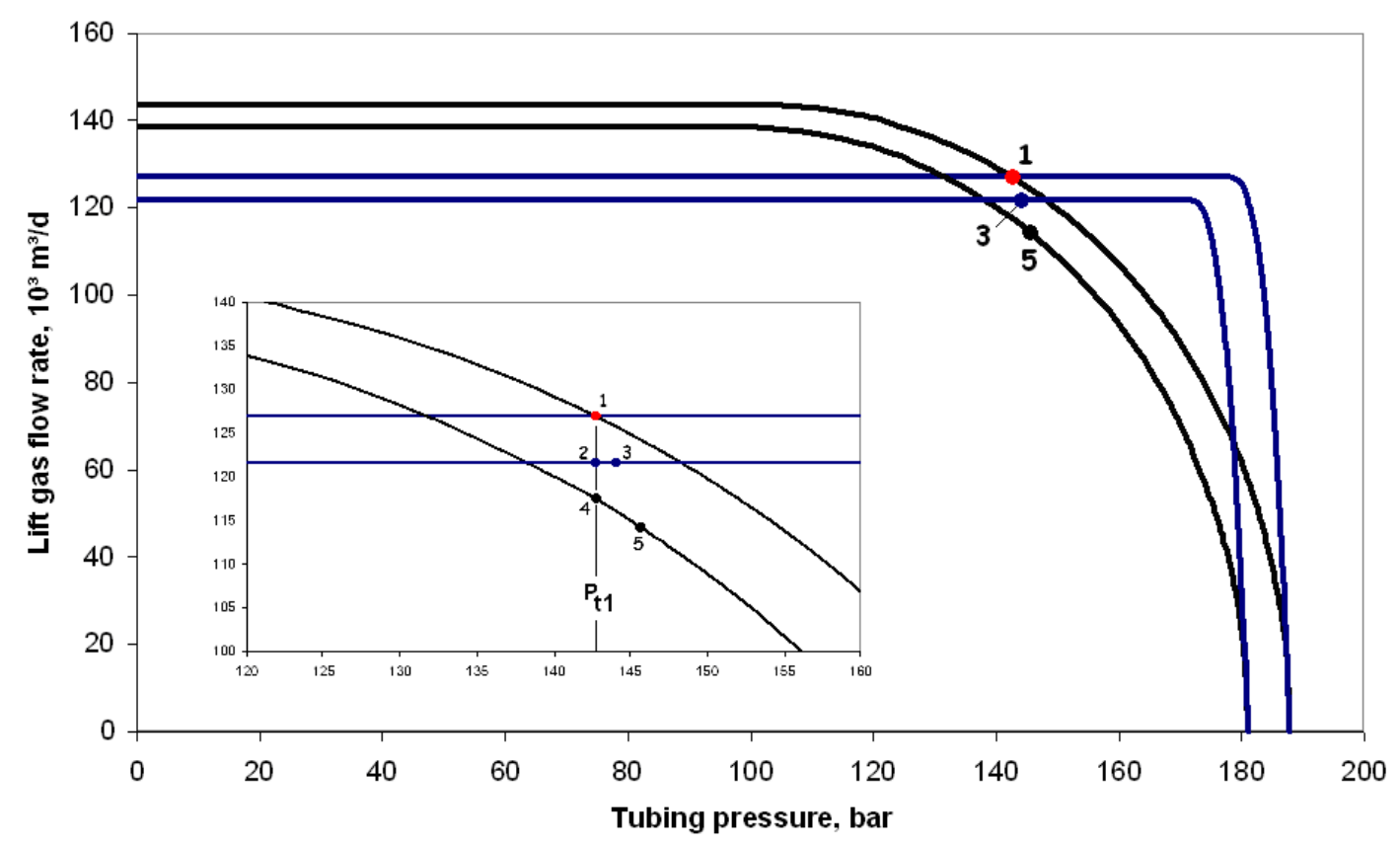

Figure 8. The difference in sensitivity to gas injection pressure is explained by the difference in performance curves between orifice and Venturi valves (gas flow rate given in standard conditions).

That difference in sensitivity to injection pressure can be better visualized with the aid of Figure 8. Performance curves for gas injection pressures of 132.4 bar and 127.5 bar are plotted for both valves. An expanded area of interest is also shown in the same figure to increase clarity. The curves have been transposed to valve depth conditions (injection pressure of 132.4 bar at the surface, for example, results in a casing pressure of 187.9 bar in front of the valve). The points used to draw the curves were also obtained by successive simulations using MARLIM, incorporating all factors influencing them. Operating point " 1 " is highlighted in red. If the tubing pressure remained constant at $P_{t 1}$ after reducing injection pressure, the new operating point for the Venturi valve would be point "2" and, for the orifice valve, point "4." This alone would represent a difference in the injection flow between the two valves for the new injection pressure. But, beyond this, the smallest injection of gas causes an increase in tubing pressure. Thus, for the Venturi valve, the operating point, instead of being point "2", will be point "3". However, this does not affect the injection flow rate as the valve continues to operate in critical flow. The injection flow rate depends on injection pressure only and it is not influenced by tubing pressure. For the orifice valve, on the other hand, this increase in tubing pressure shifts the operating point significantly, from point "4" to point "5", amplifying the reduction in gas injection.

That difference in sensitivity to injection pressure is a function of the location of the operating point on the performance curve of the orifice valve. The closer this point is to subcriticalcritical transition, the closer are the sensitivities of the two kinds of valves, orifice and Venturi.

The practical effect of that difference in sensitivity will depend on the response of the reservoir to the variation of gas injection flow rate. In general, the gas should be injected close to the so-called "optimum" point. Figure 9 shows the curve of liquid flow rate as a function of lift gas flow rate for the present example. The red circle marks the expected point of operation. Thus, the 6 bar variation in injection pressure around the operating point (see Figure 7) represents a variation of produced liquid flow rate ranging from $-1.8 \%$ to $+1.2 \%$ for the orifice valve and $\pm 0.7 \%$ for the Venturi one. For operating points closer to the "optimal" point (curve maximum), the practical effect of the difference between sensitivities would become even less important. However, in some cases, economic considerations, restrictions in gas supply, inaccurate design data among other limitations may lead to operate in a point relatively far from the optimal one, and such difference in sensitivities may become relevant. 


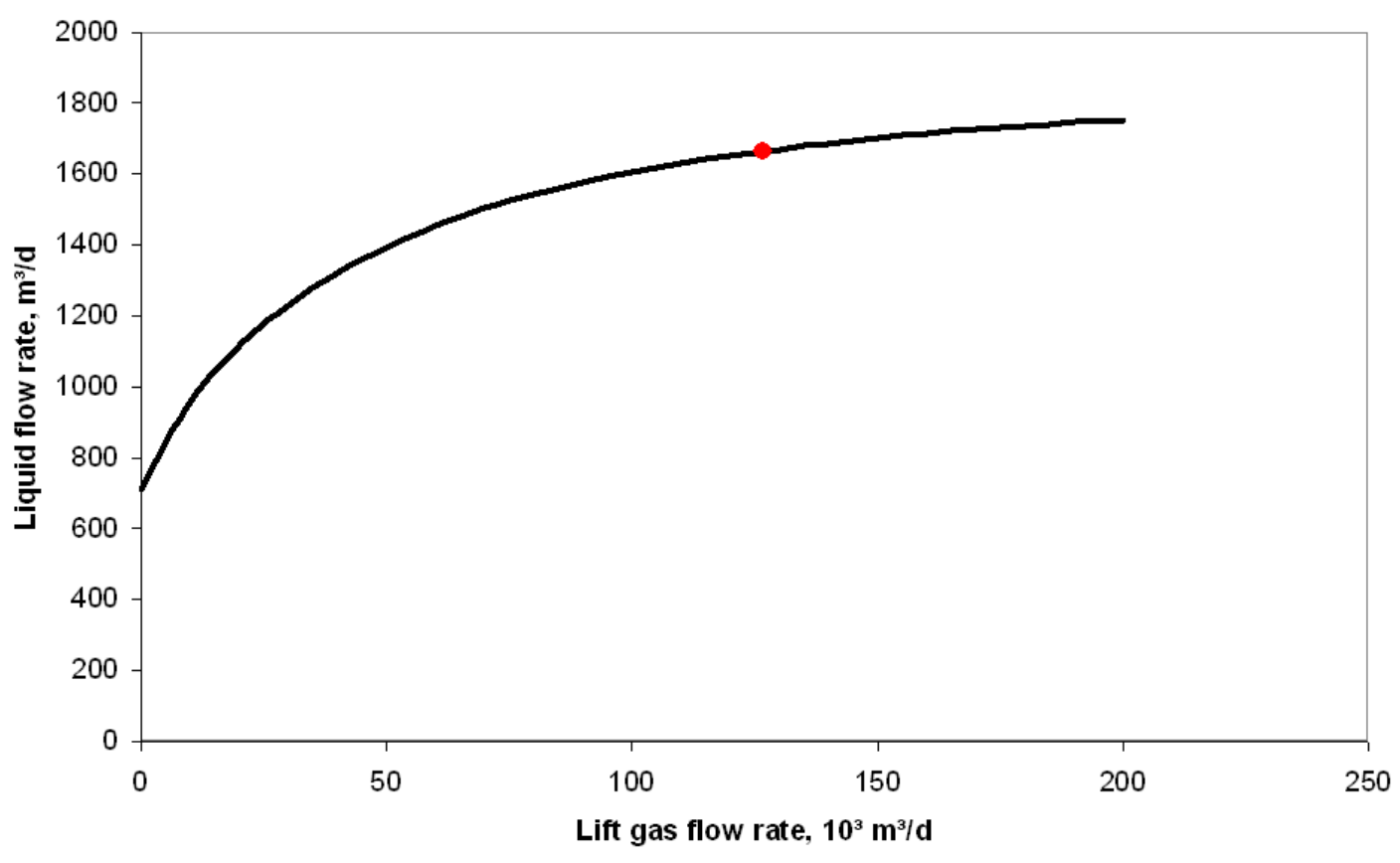

Figure 9. Well performance curve showing the relative position of the operating point (flow rates given in standard conditions).

\section{OTHER LIMITATIONS}

\subsection{Higher cost}

A Venturi is more complex to manufacture and requires more material than a simple orifice plate being, therefore, more expensive to produce. In general, the cost of Venturi valves is much higher than orifice ones not only due to the cost of the Venturi element, but because of other associated costs. Market aspects (i.e. being a new product with high tech appeal and providing potential benefits to customers) also affect the price. An analysis weighing cost and benefits should determine if it is worth or not to use a Venturi valve in a specific well.

\subsection{Blockage risk}

Existing debris in the gas stream, if present, are naturally led to the throat, where they may lodge and cause reduction in gas injection. This scenario may also occur with an orifice valve but, in this case, there is a possibility that the debris may stick onto another part of the plate without leading to a significant flow restriction. Moreover, as mentioned, for the same gas flow rate, the orifice diameter is greater than the corresponding throat diameter, allowing the passage of larger debris.
This situation is rare and, from our experience, it is unlikely to take occur (about $0.2 \%$ probability) and may be controlled. Nevertheless, it may represent a concern to old gas lift installations with known problems related to lift gas quality.

\subsection{Subcritical region}

If variations in tubing pressure are such that subcritical flow takes place, strong oscillations in gas flow rate may happen and that may create strong instabilities. Appropriate Venturi and valve design help, since the subcritical region is reduced to a minimum. But, in cases where there is a high risk of operating in subcritical flow, such issue may impact the decision of which valve to use and Venturi valves may not be recommended.

During kickoff, Venturi valves function in subcritical flow for short periods of time. The effect of that occurrence on kickoff process has not been established, but no problems regarding this have been reported. On the contrary, Venturi valves are considered better than orifice ones for kickoff because they are more resistant to erosion (Ribeiro and Lima, 2009) and, supposedly, allow steadystate operation to be reached more quickly. 


\section{CALCULATING GAS FLOW RATE}

\subsection{Critical flow modeling}

A classical reference for critical flow of gas in nozzles is the ASME/ANSI MFC-7M-1987 standard ("Measurement of Gas Flow by Means of Critical Flow Venturi Nozzles"). From that reference, the theoretical critical gas flow rate $Q_{v g p c}$ in $\mathrm{m}^{3} / \mathrm{d}$ (standard conditions) is calculated by the following equation:

$Q_{v g p c}=8640 A_{2} C_{R} \frac{P_{1}}{\rho_{\text {std }} \sqrt{R_{g} \theta_{1}}}$

where $C_{R}$ is the "critical flow coefficient" (dimensionless) and it is used to predict the deviation from ideal gas behavior. The conditions of temperature $\theta_{1}(\mathrm{~K})$ and absolute pressure $P_{1}$ (bar) upstream the Venturi are of stagnation (i.e., gas at rest). Area $A_{2}$ of the Venturi throat is given in $\mathrm{mm}^{2}$; the gas constant, $R_{g}$, in $\mathrm{J} /(\mathrm{kg} \mathrm{K})$; and the gas density at standard conditions, $\rho_{s t d}$, in $\mathrm{kg} / \mathrm{m}^{3}$.

A computer application was prepared and calculations were carried out for nitrogen and natural gas using a rigorous model presented by Almeida (2011a). A comprehensive comparison with literature data, both theoretical and experimental, was performed, validating the model (Almeida, 2011a). Values of $C_{R}$ are given in Table 1 for nitrogen and air, and in Table 2 for natural gas, considering five values of gas specific gravity, $d_{g}$

Table 1. Critical factors $C_{R}$ for nitrogen and air.

\begin{tabular}{|c|c|c|c|c|c|c|c|c|}
\hline \multirow{2}{*}{$\begin{array}{c}\text { Stagnation } \\
\text { Temperature } \\
{ }^{\circ} \mathrm{C} \\
\end{array}$} & \multicolumn{8}{|c|}{ Stagnation Pressure (absolute) in bar } \\
\hline & 0 & 25 & 50 & 100 & 150 & 200 & 250 & 300 \\
\hline \multirow[t]{2}{*}{20} & 0.6847 & 0.6909 & 0.6971 & 0.7085 & 0.7180 & 0.7250 & 0.7293 & 0.7311 \\
\hline & 0.6847 & 0.6915 & 0.6984 & 0.7112 & 0.7222 & 0.7307 & 0.7364 & 0.7397 \\
\hline \multirow[t]{2}{*}{40} & 0.6847 & 0.6896 & 0.6943 & 0.7029 & 0.7099 & 0.7150 & 0.7181 & 0.7193 \\
\hline & 0.6846 & 0.6902 & 0.6955 & 0.7054 & 0.7137 & 0.7201 & 0.7246 & 0.7271 \\
\hline \multirow[t]{2}{*}{60} & 0.6846 & 0.6885 & 0.6922 & 0.6987 & 0.7039 & 0.7075 & 0.7096 & 0.7103 \\
\hline & 0.6845 & 0.6890 & 0.6932 & 0.7009 & 0.7072 & 0.7121 & 0.7155 & 0.7174 \\
\hline \multirow[t]{2}{*}{80} & 0.6846 & 0.6876 & 0.6905 & 0.6954 & 0.6992 & 0.7017 & 0.7033 & 0.7032 \\
\hline & 0.6844 & 0.6880 & 0.6913 & 0.6974 & 0.7023 & 0.7059 & 0.7083 & 0.7096 \\
\hline \multirow[t]{2}{*}{100} & 0.6846 & 0.6869 & 0.6891 & 0.6928 & 0.6955 & 0.6971 & 0.6978 & 0.6975 \\
\hline & 0.6844 & 0.6872 & 0.6899 & 0.6945 & 0.6981 & 0.7008 & 0.7025 & 0.7032 \\
\hline \multirow[t]{2}{*}{120} & 0.6845 & 0.6863 & 0.6880 & 0.6906 & 0.6925 & 0.6934 & 0.6936 & 0.6930 \\
\hline & 0.6843 & 0.6865 & 0.6886 & 0.6921 & 0.6949 & 0.6967 & 0.6977 & 0.6980 \\
\hline \multirow[t]{2}{*}{140} & 0.6844 & 0.6858 & 0.6870 & 0.6889 & 0.6900 & 0.6905 & 0.6902 & 0.6893 \\
\hline & 0.6841 & 0.6859 & 0.6875 & 0.6902 & 0.6921 & 0.6932 & 0.6938 & 0.6936 \\
\hline \multirow[t]{2}{*}{160} & 0.6843 & 0.6853 & 0.6862 & 0.6874 & 0.6880 & 0.6880 & 0.6874 & 0.6862 \\
\hline & 0.6840 & 0.6853 & 0.6866 & 0.6884 & 0.6897 & 0.6904 & 0.6905 & 0.6899 \\
\hline \multirow[t]{2}{*}{180} & 0.6842 & 0.6849 & 0.6855 & 0.6862 & 0.6863 & 0.6859 & 0.6850 & 0.6836 \\
\hline & 0.6838 & 0.6848 & 0.6856 & 0.6870 & 0.6877 & 0.6879 & 0.6875 & 0.6867 \\
\hline \multirow[t]{2}{*}{200} & 0.6840 & 0.6845 & 0.6848 & 0.6851 & 0.6849 & 0.6842 & 0.6830 & 0.6815 \\
\hline & 0.6836 & 0.6843 & 0.6849 & 0.6857 & 0.6860 & 0.6857 & 0.6850 & 0.6840 \\
\hline
\end{tabular}


(air=1.0), and covering practical ranges of upstream pressure and temperature.

The model is rigorous and limited only by the precision of the adopted equation of state and the assumptions made (especially isentropic flow and stagnation conditions upstream of the Venturi). The equation of state is relatively simple, but the computational effort is considerably greater than that of explicit models as the classic ThornhillCraver equation (see Almeida, 2011a). Since numerical simulators may calculate flow rate through gas lift valves several times until reaching the convergence to the mathematical solution for the well liquid flow rate, application of the full model is limited. An alternative is to apply interpolation on tables of $C_{R}$ values, such as the one presented in Table 2 . Another alternative is the use of an explicit approach with acceptable loss in accuracy. Next, explicit correlations (Almeida, 2010) are presented, considering natural gas with

Table 2. Critical factors $C_{R}$ for natural gas.

\begin{tabular}{|c|c|c|c|c|c|c|c|c|}
\hline \multirow{2}{*}{$\begin{array}{c}\text { Stagnation } \\
\text { Temperature } \\
{ }^{\circ} \mathrm{C}\end{array}$} & \multicolumn{8}{|c|}{ Stagnation Pressure (absolute) in bar } \\
\hline & 0 & 25 & 50 & 100 & 150 & 200 & 250 & 300 \\
\hline \multirow[t]{5}{*}{20} & 0.6697 & 0.6859 & 0.7044 & 0.7486 & 0.7971 & 0.8370 & 0.8613 & 0.8719 \\
\hline & 0.6669 & 0.6850 & 0.7063 & 0.7594 & 0.8190 & 0.8650 & 0.8896 & 0.8978 \\
\hline & 0.6640 & 0.6846 & 0.7094 & 0.7750 & 0.8498 & 0.9016 & 0.9246 & 0.9286 \\
\hline & 0.6614 & 0.6846 & 0.7136 & 0.7962 & 0.8902 & 0.9458 & 0.9642 & 0.9623 \\
\hline & 0.6590 & 0.6852 & 0.7193 & 0.8257 & 0.9429 & 0.9978 & 1.0083 & 0.9984 \\
\hline \multirow[t]{5}{*}{40} & 0.6685 & 0.6815 & 0.6959 & 0.7286 & 0.7633 & 0.7936 & 0.8148 & 0.8265 \\
\hline & 0.6654 & 0.6800 & 0.6964 & 0.7348 & 0.7765 & 0.8119 & 0.8348 & 0.8460 \\
\hline & 0.6624 & 0.6788 & 0.6976 & 0.7436 & 0.7949 & 0.8362 & 0.8602 & 0.8698 \\
\hline & 0.6597 & 0.6780 & 0.6998 & 0.7554 & 0.8186 & 0.8658 & 0.8896 & 0.8963 \\
\hline & 0.6572 & 0.6777 & 0.7029 & 0.7710 & 0.8494 & 0.9016 & 0.9230 & 0.9254 \\
\hline \multirow[t]{5}{*}{60} & 0.6671 & 0.6777 & 0.6891 & 0.7142 & 0.7401 & 0.7633 & 0.7807 & 0.7918 \\
\hline & 0.6638 & 0.6757 & 0.6886 & 0.7176 & 0.7482 & 0.7753 & 0.7948 & 0.8062 \\
\hline & 0.6607 & 0.6739 & 0.6887 & 0.7228 & 0.7596 & 0.7914 & 0.8129 & 0.8242 \\
\hline & 0.6579 & 0.6727 & 0.6895 & 0.7297 & 0.7742 & 0.8113 & 0.8343 & 0.8447 \\
\hline & 0.6553 & 0.6718 & 0.6910 & 0.7389 & 0.7930 & 0.8356 & 0.8592 & 0.8676 \\
\hline \multirow[t]{5}{*}{80} & 0.6655 & 0.6743 & 0.6835 & 0.7032 & 0.7232 & 0.7411 & 0.7552 & 0.7648 \\
\hline & 0.6622 & 0.6719 & 0.6823 & 0.7049 & 0.7281 & 0.7490 & 0.7649 & 0.7753 \\
\hline & 0.6590 & 0.6698 & 0.6816 & 0.7078 & 0.7353 & 0.7597 & 0.7778 & 0.7887 \\
\hline & 0.6561 & 0.6682 & 0.6815 & 0.7119 & 0.7446 & 0.7732 & 0.7932 & 0.8043 \\
\hline & 0.6535 & 0.6669 & 0.6820 & 0.7175 & 0.7565 & 0.7898 & 0.8115 & 0.8222 \\
\hline \multirow[t]{5}{*}{100} & 0.6639 & 0.6712 & 0.6788 & 0.6945 & 0.7102 & 0.7242 & 0.7356 & 0.7437 \\
\hline & 0.6605 & 0.6686 & 0.6770 & 0.6950 & 0.7130 & 0.7293 & 0.7422 & 0.7512 \\
\hline & 0.6572 & 0.6662 & 0.6758 & 0.6964 & 0.7175 & 0.7365 & 0.7513 & 0.7611 \\
\hline & 0.6543 & 0.6643 & 0.6750 & 0.6987 & 0.7235 & 0.7457 & 0.7624 & 0.7728 \\
\hline & 0.6517 & 0.6628 & 0.6749 & 0.7022 & 0.7313 & 0.7572 & 0.7758 & 0.7865 \\
\hline \multirow[t]{5}{*}{120} & 0.6623 & 0.6683 & 0.6746 & 0.6874 & 0.6998 & 0.7110 & 0.7202 & 0.7268 \\
\hline & 0.6588 & 0.6656 & 0.6725 & 0.6870 & 0.7013 & 0.7142 & 0.7246 & 0.7321 \\
\hline & 0.6555 & 0.6630 & 0.6709 & 0.6874 & 0.7039 & 0.7189 & 0.7309 & 0.7393 \\
\hline & 0.6526 & 0.6609 & 0.6697 & 0.6886 & 0.7078 & 0.7252 & 0.7389 & 0.7480 \\
\hline & 0.6500 & 0.6592 & 0.6691 & 0.6906 & 0.7130 & 0.7333 & 0.7487 & 0.7585 \\
\hline
\end{tabular}

Note: In each table cell, the first line refers to pure methane $\left(d_{g}=0.5538\right)$, the second one to a natural gas with $d_{g}=0.60$, the third to $d_{g}=0.65$, the fourth to $d_{g}=0.70$, and the fifth to $d_{g}=0.75$. The first column lists ideal gas $C_{R}$ values. 
Table 2. (Cont'd). Critical factors $C_{R}$ for natural gas.

\begin{tabular}{|c|c|c|c|c|c|c|c|c|}
\hline \multirow{2}{*}{$\begin{array}{c}\text { Stagnation } \\
\text { Temperature } \\
{ }^{\circ} \mathrm{C}\end{array}$} & \multicolumn{8}{|c|}{ Stagnation Pressure (absolute) in bar } \\
\hline & 0 & 25 & 50 & 100 & 150 & 200 & 250 & 300 \\
\hline \multirow[t]{5}{*}{120} & 0.6623 & 0.6683 & 0.6746 & 0.6874 & 0.6998 & 0.7110 & 0.7202 & 0.7268 \\
\hline & 0.6588 & 0.6656 & 0.6725 & 0.6870 & 0.7013 & 0.7142 & 0.7246 & 0.7321 \\
\hline & 0.6555 & 0.6630 & 0.6709 & 0.6874 & 0.7039 & 0.7189 & 0.7309 & 0.7393 \\
\hline & 0.6526 & 0.6609 & 0.6697 & 0.6886 & 0.7078 & 0.7252 & 0.7389 & 0.7480 \\
\hline & 0.6500 & 0.6592 & 0.6691 & 0.6906 & 0.7130 & 0.7333 & 0.7487 & 0.7585 \\
\hline \multirow[t]{5}{*}{140} & 0.6606 & 0.6657 & 0.6709 & 0.6814 & 0.6915 & 0.7004 & 0.7078 & 0.7132 \\
\hline & 0.6572 & 0.6628 & 0.6686 & 0.6804 & 0.6919 & 0.7022 & 0.7106 & 0.7168 \\
\hline & 0.6539 & 0.6601 & 0.6666 & 0.6801 & 0.6933 & 0.7052 & 0.7149 & 0.7219 \\
\hline & 0.6510 & 0.6579 & 0.6652 & 0.6805 & 0.6957 & 0.7096 & 0.7206 & 0.7284 \\
\hline & 0.6484 & 0.6561 & 0.6642 & 0.6816 & 0.6992 & 0.7152 & 0.7278 & 0.7363 \\
\hline \multirow[t]{5}{*}{160} & 0.6590 & 0.6633 & 0.6677 & 0.6763 & 0.6845 & 0.6917 & 0.6976 & 0.7020 \\
\hline & 0.6555 & 0.6603 & 0.6652 & 0.6749 & 0.6842 & 0.6925 & 0.6993 & 0.7043 \\
\hline & 0.6523 & 0.6576 & 0.6630 & 0.6740 & 0.6847 & 0.6943 & 0.7021 & 0.7079 \\
\hline & 0.6494 & 0.6553 & 0.6614 & 0.6738 & 0.6861 & 0.6972 & 0.7062 & 0.7127 \\
\hline & 0.6469 & 0.6534 & 0.6602 & 0.6743 & 0.6884 & 0.7012 & 0.7115 & 0.7187 \\
\hline \multirow[t]{5}{*}{180} & 0.6574 & 0.6611 & 0.6647 & 0.6719 & 0.6786 & 0.6845 & 0.6892 & 0.6928 \\
\hline & 0.6540 & 0.6580 & 0.6621 & 0.6702 & 0.6778 & 0.6845 & 0.6900 & 0.6940 \\
\hline & 0.6508 & 0.6553 & 0.6598 & 0.6690 & 0.6777 & 0.6855 & 0.6918 & 0.6965 \\
\hline & 0.6480 & 0.6529 & 0.6580 & 0.6684 & 0.6784 & 0.6873 & 0.6946 & 0.6999 \\
\hline & 0.6455 & 0.6510 & 0.6567 & 0.6683 & 0.6798 & 0.6901 & 0.6984 & 0.7045 \\
\hline \multirow[t]{5}{*}{200} & 0.6559 & 0.6590 & 0.6621 & 0.6681 & 0.6736 & 0.6784 & 0.6822 & 0.6850 \\
\hline & 0.6525 & 0.6560 & 0.6594 & 0.6661 & 0.6724 & 0.6778 & 0.6823 & 0.6855 \\
\hline & 0.6494 & 0.6532 & 0.6570 & 0.6647 & 0.6718 & 0.6781 & 0.6833 & 0.6870 \\
\hline & 0.6466 & 0.6508 & 0.6552 & 0.6638 & 0.6720 & 0.6792 & 0.6852 & 0.6895 \\
\hline & 0.6442 & 0.6489 & 0.6537 & 0.6634 & 0.6728 & 0.6811 & 0.6880 & 0.6929 \\
\hline
\end{tabular}

Note: In each table cell, the first line refers to pure methane $\left(d_{g}=0.5538\right)$, the second one to a natural gas with $d_{g}=0.60$, the third to $d_{g}=0.65$, the fourth to $d_{g}=0.70$, and the fifth to $d_{g}=0.75$. The first column lists ideal gas $C_{R}$ values.

specific gravity $d_{g}$ from 0.5538 to 0.75 with very small amounts of $\mathrm{N}_{2}, \mathrm{CO}_{2}$, or $\mathrm{H}_{2} \mathrm{~S}$, stagnation upstream pressure up to 300 bar and stagnation upstream temperature between $20^{\circ} \mathrm{C}$ and $200{ }^{\circ} \mathrm{C}$.

The following equation is to be used for natural gas with $d_{g}=0.5538$ or $d_{g}=0.7500$ :

$$
\begin{aligned}
\frac{1}{C_{R}} & =\sum_{i=1}^{3} a_{i} P_{1}^{(i-1)}-\left(\sum_{i=4}^{8} \frac{a_{i} P_{1}^{(i-4)}}{\theta_{1}}\right)^{b} \\
b & =\sum_{i=9}^{14} a_{i} P_{1}^{(i-9)}
\end{aligned}
$$

For intermediate gravities, calculate $C_{R}$ for $d_{g}=$ $0.5538\left(C_{R ; d g=0.5538}\right)$ and for $d_{g}=0.7500\left(C_{R ; d g=0.75}\right)$ with Equations (2a-b), and apply the following interpolation equation:

$$
\begin{gathered}
C_{R}=C_{R ; d_{g}=0.5538}+3.967819 \times \\
\times\left[C_{R ; d_{g}=0.75}-C_{R ; d_{g}=0.5538}\right]\left[\left(d_{g}\right)^{3}\right. \\
-0.1698474]
\end{gathered}
$$

Some experimental facilities use nitrogen or air to test gas lift valves. The $C_{R}$ for nitrogen may be calculated with the following correlation $\left(P_{1}\right.$ up to 300 bar and $\theta_{1}$ between $0{ }^{\circ} \mathrm{C}$ and $200{ }^{\circ} \mathrm{C}$ ):

$$
C_{R, N_{2}}=a_{1}+P_{1}\left(a_{2}+a_{3} P_{1}\right) \sum_{i=4}^{8} a_{i}\left(\frac{\theta_{1}}{100}\right)^{(i-4)}
$$


Table 3. Coefficients $a_{i}$ for $C_{R}$ correlations.

\begin{tabular}{|c|c|c|c|}
\hline \multirow{2}{*}{$a_{i}$} & \multirow{2}{*}{$\mathrm{N}_{2}$} & \multicolumn{2}{|c|}{ Natural Gas } \\
\hline & & $d_{g}=0.5538$ & $d_{g}=0.7500$ \\
\hline 1 & $6.848228 \mathrm{E}-01$ & $1.634214 \mathrm{E}+00$ & $1.643304 \mathrm{E}+00$ \\
\hline 2 & 5.475800E-01 & $-1.041542 \mathrm{E}-03$ & $-1.690827 E-03$ \\
\hline 3 & $-7.985775 E-04$ & 3.517203E-06 & 7.678912E-06 \\
\hline 4 & 2.191862E-02 & $-1.168549 E+01$ & $3.179417 \mathrm{E}+00$ \\
\hline 5 & $-2.053041 E-02$ & $2.613943 E+00$ & 4.310207E+00 \\
\hline 6 & 7.441355E-03 & $-1.015222 \mathrm{E}-02$ & $-2.798734 \mathrm{E}-02$ \\
\hline 7 & $-1.221873 E-03$ & $1.273096 \mathrm{E}-05$ & 7.897964E-05 \\
\hline 8 & 7.591276E-05 & $9.910994 \mathrm{E}-10$ & $-8.010277 E-08$ \\
\hline 9 & - & $6.460394 \mathrm{E}-01$ & $9.578202 E-01$ \\
\hline 10 & - & 8.188871E-03 & $1.545911 \mathrm{E}-02$ \\
\hline 11 & - & $3.238264 \mathrm{E}-04$ & 7.379477E-04 \\
\hline 12 & - & $-3.019772 E-06$ & $-8.477320 \mathrm{E}-06$ \\
\hline 13 & - & $9.392400 \mathrm{E}-09$ & 3.076955E-08 \\
\hline 14 & - & $-1.014394 \mathrm{E}-11$ & $-3.732852 E-11$ \\
\hline
\end{tabular}

Finally, the $C_{R}$ for air may be estimated from the corresponding value for nitrogen using a correlation presented by Almeida (2011a):

$\frac{C_{R, \text { air }}}{C_{R, N_{2}}}=1.0008-2.9152 \times 10^{-6} \theta_{1}$

$-1.3975 \times 10^{-7} P_{1}\left(\theta_{1}-574.20\right)$

The coefficients $a_{i}$ required by Equations (2a-b) and (3) are given in Table 3.

The comparison of the correlations against the rigorous calculation of $C_{R}$ with the model presented by Almeida (2011a), in the range of interest for $P_{1}$, $\theta_{1}$, and $d_{g}$, shows an absolute average deviation of $0.27 \%$ and a maximum one of $1.12 \%$ for natural gas, Equations (2a-c). For nitrogen, Equation (3), the corresponding deviations are $0.09 \%$ and $0.34 \%$, respectively. For air, Equation (4), the maximum error is estimated to be less than $1 \%$.

Once $C_{R}$ is obtained, critical gas flow rate may be calculated by Equation (1). Considering standard conditions as atmospheric pressure and $20^{\circ} \mathrm{C}, \rho_{\text {std }}$ for nitrogen is $1.16498 \mathrm{~kg} / \mathrm{m}^{3}$ and, for natural gas, it may be obtained (Almeida, 2011a) as a function of specific gravity $d_{g}$ by:

$\rho_{s t d}=1.20761 d_{g}$

If the standard temperature is $60^{\circ} \mathrm{F}, \rho_{\text {std }}$ for nitrogen is $1.18296 \mathrm{~kg} / \mathrm{m}^{3}$ and, for natural gas, the new coefficient in Equation (5) is 1.22637.

The rigorous model described by Almeida (2011a) calculates theoretical gas flow rates. For real Venturi valves, the assumptions made are not fully valid. To correct such differences, a dimensionless "discharge coefficient", $C_{D}$, is usually introduced multiplying the right side of Equation (1). That coefficient is usually evaluated experimentally. If an accurate model is used and the Venturi valve is well designed, $C_{D}$ is close to 1. 


\subsection{Subcritical flow modeling}

Subcritical regime is highly relevant for orifice and similar valves, which nearly always operate in subcritical flow. Since Venturi gas lift valves are intended to operate always in critical flow, the main concern is to model critical flow instead of subcritical flow. However, although the accurate modeling for the subcritical region is not required for steady-state simulations (well operation), its relevance for transient simulations (well discharge, for example) is not established. To complete the model described above, we propose a modeling for the subcritical region.

In the case of an orifice valve, the tubing pressure is close to that of the main restriction. This occurs because the pressure recovery downstream the main restriction is usually very low, see Figure 2 . Then, given a tubing pressure $P_{3}$, one has $\Psi_{p 2}=P_{2} / P_{1} \approx \Psi_{p 3}=P_{3} / P_{1}$. In the Venturi valve, due to the great recovery of pressure at the diffuser, $P_{2}$ differs considerably from $P_{3}$, as can be observed in Figure 2, creating the need for a procedure to calculate $P_{2}$ from $P_{3}$. One approach is to assume that the pressure recovery factor, $F_{P R}$, defined by Equation (6), is constant and dependent only on throat diameter (Almeida, 2014).

$F_{P R}=\frac{P_{3}-P_{2}}{P_{1}-P_{2}}=\frac{P_{3} / P_{1}-P_{2} / P_{1}}{1-P_{2} / P_{1}}=\frac{\Psi_{p 3}-\Psi_{p 2}}{1-\Psi_{p 2}}$

Given $F_{P R}$, the pressure $P_{2}$ may be calculated from $P_{1}$ and $P_{3}$. If $P_{1}$ is constant, and $P_{3}$ is reduced continuously, the pressure at the throat, $P_{2}$, decreases continuously, accordingly. The flow rate increases until $P_{2}$ reaches the critical pressure, $P_{2 c}$, for which the velocity at the throat is sonic and any further reduction in $P_{3}$ does not change $P_{2}$ or the flow rate. The corresponding downstream critical pressure is $P_{3 c}$. If $P_{3}$ is reduced below $P_{3 c}$, a shock will happen somewhere after the throat, to accommodate pressure changes from $P_{2 c}$ to $P_{3}$.

The theoretical critical ratio at the Venturi throat, $\Psi_{p 2 c}=P_{2 c} / P_{1}$, may be obtained from models as the one presented in Almeida (2011a). The critical ratio of the whole valve, $\Psi_{p 3 c}=P_{3 c} / P_{1}$, may be evaluated from experimental curves as the one shown in Figure 1. It may be estimated by direct reading from the curve, but sometimes it is difficult to accurately establish the critical point due to fluctuations in flow rate during the transition from subcritical to critical flow. A better procedure is to apply a mathematical model to the experimental data and find the values of $F_{P R}$ and $C_{D}$ that result in the best match. Almeida (2014) employed that approach to model nozzle gas lift valves, which usually operate in subcritical flow.

In the absence of information, $\Psi_{p 3 c}=0.9\left(F_{P R}=\right.$ 0.8 ) is a conservative estimate for good quality 1.5in OD Venturi gas lift valves with throat diameters

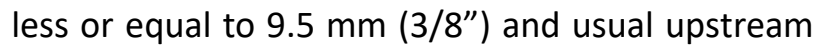
conditions and gas composition (at least for the Petrobras scenario). For 1 -in OD valves, this limit throat diameter is, generally, $8.0 \mathrm{~mm}\left(5 / 16^{\prime \prime}\right)$.

Once $P_{2}$ is known and $P_{2}>P_{2 c}$, the rigorous model presented by Almeida (2011a) may be applied, calculating the isentropic flow from $P_{1}$ to $P_{2}$. Another procedure, based on the well-known Thornhill-Craver equation, and that is relatively accurate ( $\pm 5 \%$ error) for pressures $P_{1}$ up to $150 \mathrm{bar}$ is described in Almeida (2014). This modified Thornhill-Craver equation can be written as follows:

$Q_{v g p}=423.47 A_{2} P_{1} \sqrt{\frac{2 \frac{\zeta}{\zeta-1}\left(\Psi_{p 2}^{\frac{2}{\zeta}}-\Psi_{p 2}^{\frac{\zeta+1}{\zeta}}\right)}{d_{g} z_{1} \theta_{1}}}$

where $Q_{v g p}$ is the gas flow rate at standard conditions (atmospheric pressure and $20^{\circ} \mathrm{C}$ ) in $\mathrm{m}^{3} / \mathrm{d}, z_{1}$ is the gas compressibility factor for upstream conditions $\left(P_{1}\right.$ and $\left.\theta_{1}\right)$, and $\zeta$ is the ratio of ideal gas specific heats $\left(=c_{P 0} / c_{V 0}\right.$, where $c_{P 0}$ is the ideal gas specific heat at constant pressure and $c_{V_{0}}$ is the ideal gas specific heat at constant volume). The remaining symbols follow the previously cited definitions and units. For natural gas, it is usual in the literature to adopt $\zeta \approx 1.3$.

Given $F_{P R}$, if the calculated $P_{2}$ is lower than $P_{2 c}$, then, replace $\Psi_{p 2}$ in Equation (7) by $\Psi_{p 2 c}=P_{2 c} / P_{1}$, the critical pressure ratio. In critical flow, the flow rate reaches a maximum. As a consequence, $\Psi_{p 2 c}$ may be obtained by differentiating Equation (7) with respect to $\Psi_{p 2}$ and equaling it to zero. This value of $\Psi_{p 2 c}$ is linked to the simplifying hypothesis involved in Equation (7) and is given by:

$\Psi_{p 2 c}=\left(\frac{2}{\zeta+1}\right)^{\frac{\zeta}{\zeta-1}}$

Using the typical value $\zeta=1.3$, then, $\Psi_{p 2 c}=$ 0.5457 . 
Equation (7), along with the concepts of recovery factor, $F_{P R}$, and discharge coefficient, $C_{D}$, allows the estimation of gas flow rates for both, critical and subcritical regions, with precision limited by the simplifying hypothesis involved in its derivation (see Almeida, 2011a). However, for associated use with the rigorous model (or with the simplified $C_{R}$ relations), just to calculate flow rates in the subcritical region, it is necessary to introduce two corrections.

First, since the calculated critical pressure ratios at throat are different, obtain a pseudo- $\Psi_{p 2}, \Psi_{p 2, T c}$, to use in Equation (7), following the proportion in the respective subcritical regions as:

$\Psi_{p 2, T C}=1-\left(\frac{1-\Psi_{p 2 c, T C}}{1-\Psi_{p 2 c, r m}}\right)\left(1-\Psi_{p 2}\right)$

where $\Psi_{p 2 c, T c}$ is the pressure critical ratio calculated by Equation (8) and $\Psi_{p 2 c, r m}$ is the pressure critical ratio calculated by the rigorous model.

Second, correct the flow rates multiplying the results of Equation (7) by:

$C_{Q}=\frac{Q_{v g p c, r m}}{Q_{v g p c, T C}}$

where $Q_{v g p c, r m}$ and $Q_{v g p c, T c}$ refer to the calculated critical flow rates, respectively, by the rigorous model, Equation (1), and by the Thornhill-Craver model, Equation (7) with $\Psi_{p 2}$ replaced by $\Psi_{p 2 c}$ from Equation (8).

Another approach (Almeida, 2010) is to apply the following empirical equation for the subcritical region $\left(P_{3 c} / P_{1}=\Psi_{p 3 c}<\Psi_{p 3} \leq 1.0\right)$ :

$$
\begin{aligned}
& Q_{v g p}=Q_{v g p c} \times\left[1+\left(\Psi_{p 3}-\Psi_{p 3 c}\right)^{3}\right] \times \\
& \times\left[1-\left(\frac{\Psi_{p 3}-\Psi_{p 3 c}}{1-\Psi_{p 3 c}}\right)^{2.5}\right]
\end{aligned}
$$

Although less precise, Equation (10) is a simple and direct approach when a qualitative subcritical region suffices.

\subsection{Numerical examples}

To exemplify the calculations, consider a Venturi with $6.35 \mathrm{~mm}\left(1 / 4^{\prime \prime}\right)$ throat diameter. It is required to calculate the theoretical critical flow rate for natural gas with 0.65 specific gravity. The upstream (stagnation) absolute conditions are 250 bar and $353 \mathrm{~K}\left(\approx 80^{\circ} \mathrm{C}\right)$. Calculations of properties as indicated by Almeida (2011a) yield $z_{1}=0.8979$ and $\zeta=1.24$.

Critical flow (rigorous model). The approximate relative molecular mass of natural gas is given by $M_{g} \approx M_{\text {air }} \times d_{g}$. For the present case, $M_{g} \approx 28.97 \times$ $0.65=18.83$. The gas constant $R_{g}$ is the universal gas constant $R_{u}=8314.34 \mathrm{~J} /(\mathrm{kmol} \mathrm{K})$ divided by $M_{g}$. Then, $\mathrm{Rg}=8314.34 / 18.83=441.5 \mathrm{~J} /(\mathrm{kg} \mathrm{K})$. Equation (5) gives $\rho_{\text {std }}=1.20761 \times 0.65=0.7849 \mathrm{~kg} / \mathrm{m}^{3}$. The throat area is $A_{2}=(\pi / 4) \times(6.35)^{2}=31.67 \mathrm{~mm}^{2}$. From Table 2, the ASME $C_{R}$ is 0.7778 . Applying Equation (1) results in:

$$
\begin{aligned}
& Q_{v g p c}=8640 \times 31.67 \times 0.7778 \times \\
& \times \frac{250}{0.7849 \sqrt{441.5 \times 353}}=1.717 \times 10^{5} \mathrm{~m}^{3} / \mathrm{d}
\end{aligned}
$$

Using the rigorous model (Almeida, 2011a), the theoretical critical conditions and velocity at the throat are 126.7 bar (absolute; critical pressure ratio at throat of 0.5070$), 32.84{ }^{\circ} \mathrm{C}$, and $403.9 \mathrm{~m} / \mathrm{s}$, respectively. If experimental curves, similar to Figure 1 , are available to this particular valve model, a discharge coefficient may be obtained and applied, resulting in a better estimate of the real gas flow rate.

Critical flow (correlation on $C_{R}$ ). Using Equations (2a-b), one can obtain $C_{R}=0.75465$ for a $d_{g}=0.5538$ gas and $C_{R}=0.81572$ for a $d_{g}=0.75$ gas. Interpolating for $d_{g}=0.65$ with Equation $(2 \mathrm{c})$, one can get $C_{R}=0.7800$, which represents a calculated flow rate from Equation (1) of $1.722 \times 10^{5} \mathrm{~m}^{3} / \mathrm{d}$, a $0.3 \%$ difference from the rigorous model.

Critical flow (modified Thornhill-Craver). From Equation (8), $\Psi_{p 2 c}=0.5568$. Applying Equation (7):

$Q_{v g p c}=423.47 \times 31.67 \times 250 \times$

$\times \sqrt{\frac{2 \times \frac{1.24}{0.24} \times\left(0.5568^{\frac{2}{1.24}}-0.5568^{\frac{2.24}{1.24}}\right)}{0.65 \times 0.8979 \times 353}}$

$=1.533 \times 10^{5} \mathrm{~m}^{3} / \mathrm{d}$

a difference of $11 \%$ from the rigorous model.

Now, it is required to estimate the gas flow rate for subcritical flow with the downstream (tubing) absolute pressure of 240 bar (maintaining 
remaining data values). Consider $\Psi_{p 3 c}=0.9000$.

Subcritical flow (rigorous model). Although beyond the scope of the present article, the calculations follow the same procedure depicted by Almeida (2011a). The gas flow rate for $\Psi_{p 3}=$ $240 / 250=0.9600$ is $1.357 \times 10^{5} \mathrm{~m}^{3} / \mathrm{d}$.

Subcritical flow (modified Thornhill-Craver). It is necessary to calculate $\Psi_{p 2}$. In this case, $\Psi_{p 3 c}$ is given. Writing Equation (6) for the critical point, $F_{R}$ is calculated as:

$F_{R}=\frac{\Psi_{p 3 c}-\Psi_{p 2 c}}{1-\Psi_{p 2 c}}=\frac{0.9000-0.5070}{1-0.5070}=0.7972$

Applying Equation (6) again, $\Psi_{p 2}$ is obtained:

$F_{R}=0.7972=\frac{0.9600-\Psi_{p 2}}{1-\Psi_{p 2}} \rightarrow \Psi_{p 2}=0.8028$

From Equations (9a) and (9b), one can obtain $\Psi_{p 2, T C}$ and $C_{Q}$ as:

$\Psi_{p 2, T C}=1-\left(\frac{1-0.5568}{1-0.5070}\right)(1-0.8028)=$

$=0.8227$

$C_{Q}=\frac{1.717 \times 10^{5}}{1.533 \times 10^{5}}=1.120$

Now, Equation (7) may be applied, multiplying it by $C_{Q}$ and using $\Psi_{p 2, T c}$ as $\Psi_{p 2}$ :

$Q_{v g p}=1.120 \times 423.47 \times 31.67 \times 250 \times$

$\times \sqrt{\frac{2 \times \frac{1.24}{0.24} \times\left(0.8227^{\frac{2}{1.24}}-0.8227^{\frac{2.24}{1.24}}\right)}{0.65 \times 0.8979 \times 353}}=$

$=1.383 \times 10^{5} \mathrm{~m}^{3} / \mathrm{d}$

a difference of $2 \%$ from the rigorous model.

Subcritical flow (empirical equation). Equation (10) yields:

$Q_{v g p}=1.717 \times 10^{5} \times$

$\times\left[1+(0.9600-0.9000)^{3}\right] \times$

$\times\left[1-\left(\frac{0.9600-0.9000}{1-0.9000}\right)^{2.5}\right]=$

$=1.238 \times 10^{5} \mathrm{~m}^{3} / \mathrm{d}$

a difference of $9 \%$ from the rigorous model.

\section{PERFORMANCE CONCERNS}

In a Venturi valve, some design requirements must be fulfilled to guarantee the desired performance. Not only must the Venturi itself follow an appropriate profile and finishing but the entry ports and the check valve must introduce as small pressure losses as possible. It is advisable that gas lift engineers pay attention to some key points to avoid surprises related to poor performance.

The Venturi geometry is well-known and standardized in cases where such elements are used for flow measurement, see ASME/ANSI MFC7M-1987 standard. However, small geometric variations can exist between designs that result in different levels of efficiency. Almeida (2015) describes key design points, including a recommended Venturi geometry, the influence of several Venturi design parameters in performance, and an analysis of the check valve role. The design guidelines proposed are supported by experimental tests performed at Petrobras' Gas Lift Valves Test Unit (UTVGL) and the vast experience on Venturi valves after more than 600 valves run in wells or tested.

The Venturi inner surface finishing is also important and will directly influence pressure recovery through diffuser. This is one of the factors that must be taken into consideration when choosing the material and manufacturing process. The Venturi should be visually inspected to ensure that there are no defects, especially at or near the transition between nozzle and throat and/or between throat and diffuser.

Tight dimensional tolerance in throat diameter is also important since operation in critical flow means that flow rate is directly proportional to throat area. For a prescribed tolerance of $x \%$ in the critical flow rate, for example, it is required a dimensional tolerance of $x \%$ in the throat area, i.e., $(x / 2) \%$ in the throat diameter, approximately. It is also advisable to confirm with the manufacturers the real throat diameter that corresponds to the nominal one since some differences may occur due to fabrication issues. In general, such differences are very small but, in the case of Venturi valves, they may represent a significant difference in flow rates.

A good Venturi design is not sufficient. The 
overall valve critical ratio may be severely affected by local pressure losses at entry ports and at check valve/exit ports. More and larger entry ports are required in comparison with conventional orifice valves. The entry section has to present an external diameter smaller than that of the rest of the valve's body, allowing a sufficiently large annular area between the valve housing in the mandrel and the valve itself. The check valve must have a gas passage area as large as possible. The importance of a good check valve design was demonstrated in a previous work (Mendes and Almeida, 2008) using CFD technique. Additionally, internal channels of the valve as a whole should also be expanded. It is also recommended to review the mandrel because larger entry orifices and gas passage areas would be probably beneficial, particularly for high gas flow rates. ${ }^{3}$

Even a well-designed Venturi valve has a limited gas flow rate. Beyond that limit, performance degrades, especially in terms of critical ratio. Although pressure and temperature conditions influence these limits, it is recommended to limit throat diameters to $8.0 \mathrm{~mm} \mathrm{(5/16} \mathrm{in)} \mathrm{for} 1$-in OD valves and $9.5 \mathrm{~mm}(3 / 8 \mathrm{in})$ for 1.5-in OD valves. Larger throats may be used but the gas lift engineer has to consider that using larger throats will probably result in critical ratios lower than 0.90. Alternatively, two Venturi valves may be employed to divide flow rate. The use of two orifice valves to inject the desired gas flow rate is not new, but practice has shown that it hardly works, particularly if the valves depths are close in the well. Valves' dynamic behaviors interfere on each other impairing control and resulting in gas flow rates generally unstable and lower than those calculated previously. Nevertheless, two Venturi valves in critical flow will not be affected in this manner, and the chances of them working properly are good. Another possibility is the use of two Venturis in the same valve, one injecting upwards and the other downwards. However, these solutions introduce an additional possible failure or leak point in the tubing and that concern must be evaluated. A better solution is to use a 1.75 -in OD

\footnotetext{
${ }^{3}$ However, it is worth mentioning that a direct adaptation of an orifice valve, replacing the orifice plate with a Venturi, may work reasonably well for small throat diameters (for example, a Venturi with a throat diameter of $3.0 \mathrm{~mm}$ in a 1-in OD orifice valve). CFD analysis and experimental tests may help define the maximum throat diameter that may be used for a specific orifice valve model.
}

valve, which allows for larger throats, while maintaining good performance.

Despite all considerations above, practice has shown that it is advisable to do performance tests on every gas lift valve to be run on subsea wells, and compare the curves found with previous ones, i.e., with a "signature" of the valve. An alternative is to perform some basic tests and an in-depth inspection of each valve. Such procedures have identified many unexpected problems before sending the valve to a well.

Venturis are usually provided in discrete diameters with 1/32-inch step between them (approximately $0.8 \mathrm{~mm}$ ). For orifice valves, such diameter sequence works well. They operate under subcritical flow and, in general, respond strongly to variations in injection pressure, making it easy to obtain the desired injection flow rate. As shown previously, Venturi valves are different: they operate in critical flow and injection of gas is less sensitive to adjustments in casing pressure. When the gas lift designer defines the required gas flow rate and, as a consequence, the throat diameter, he/she has to choose in the available sequence the Venturi that is closest to the calculated one. This may mean a decision between injecting more or less gas than required within a relatively large margin. One possibility is to manufacture custom made Venturis, what may be commercially impractical. Thus, a sequence that minimizes the differences in gas flow between a diameter and the next would be very useful. Therefore, instead of a sequence based on increments in diameter, a sequence based on increments in area is advisable. In this case, it is recommended an area increment of $15 \%$ or less.

\section{CONCLUSION}

The Venturi gas lift valve is now a standard equipment and a mature technology at Petrobras. It has been preferred over orifice valves, particularly for offshore wells. In the author's opinion, the main restriction to general use of Venturi gas lift valves are in the cases where there is a need for large adjustments in gas flow rate over time within a limited injection pressure range, and changing the valve is not possible or economical. 
The author's experience has shown that it is worth for operators to develop expertise in key artificial lift equipment and, if possible, to have access to experimental facilities to study and evaluate them.

\section{REFERENCES}

Alhanati, F. J. S.; Schmidt, Z.; Doty, D. R.; Lagerlef, D. D. Continuous gas-lift instability: diagnosis, criteria, and solutions. SPE Annual Technical Conference and Exhibition, 3-6 October, Houston, 1993. https://doi.org/10.2118/26554-MS

Aliyeva, F.; Novruzaliyev, B. Gas lift - fast and furious. SPE Annual Caspian Technical Conference and Exhibition, 4-6 November, Baku, 2015. https://doi.org/10.2118/177359-MS

Almeida, A. R. Calculating gas flow rates through venturi valves. Oil \& Gas Journal, v. 108 (5), p. 4145, 2010.

Almeida, A. R. A Model to calculate the theoretical critical flow rate through Venturi gas lift valves. SPE Journal, v. 16 (1), p. 134-147, 2011a (addendum included in the digital version at OnePetro in January 2014).

https://doi.org/10.2118/126184-PA

Almeida, A. R. Advantages and limitations of venturi gas lift valves. World Oil, v. 232 (7), p. 7179, 2011b.

Almeida, A. R. Advantages of a new nozzle valve for gas lift. World Oil, v. 235 (10), p. 115-119, 2014.

Almeida, A. R. Some design aspects for venturi gas lift valves. SPE Production \& Operations, v. 30 (4), p. 321-328, 2015.

https://doi.org/10.2118/174092-PA

Almeida, A. R.; Gonçalves, M. A. L. Venturi for severe slugging elimination. $\mathbf{9}^{\text {th }}$ International Conference Multiphase '99 (BHR Group), 16-18 June, Cannes, 1999.

Almeida, A. R.; Slobodcicov, I. Continuous gas lift performance analysis. World Oil, v. 219 (9), p. 91-96, 1998.

Faustinelli, J.; Bermúdez, G.; Cuauro, A. A Solution to instability problems in continuous gaslift wells offshore Lake Maracaibo. SPE Latin American \& Caribbean Petroleum Engineering Conference, 21-23 April, Caracas, 1999. https://doi.org/10.2118/53959-MS
Grupping, A. W.; Luca, C. W. F.; Vermeulen, F. D. These methods can eliminate or control annulus heading. Oil \& Gas Journal, v. 82 (31), p. 186-192, 1984.

Hanson, E. S. Pilot gas-lift system at Prudhoe Bay. SPE California Regional Meeting, 27-29 March, Bakersfield, 1985.

https://doi.org/10.2118/13635-MS

Hu, B.; Golan, M. Gas-lift instability resulted production loss and its remedy by feedback control: Dynamical simulation results. SPE International IOR Conference in Asia Pacific, 20-21 October, Kuala Lumpur, 2003.

Kartoatmodjo, G.; Strasser, R.; Caretta, F.; Jadid, M.; Bakar, G.; Liew, J. An integrated approach to field surveillance improves efficiency in gas lift optimization in Bokor Field, East Malaysia. International Petroleum Technical Conference, 3-5 December, Kuala Lumpur, 2008.

https://doi.org/10.2523/12225-MS

Lyngholm, A.; Opsal, M.; White, T.; Boerve, E. Technology extends gas lift reach. World Oil, v. 228 (4), p. 95-98, 2007.

Mendes, R.; Almeida, A. R. Optimizing gas lift equipment with CFD techniques. $\mathbf{3 1}^{\text {st }}$ ASME/API/ISO Gas Lift Workshop, 4-8 February, Houston, 2008 (available at www.alrdc.org ).

Moore, P. C.; Adair, P. Dual concentric gas-lift completion design for the Thistle Field. SPE Production Engineering, v. 6 (1), p. 102-108, 1991. https://doi.org/10.2118/18391-PA

Mota, B. R.; Alves, S. J.; Reis, L. C. Optimizing the Barracuda and Caratinga subsea well design to improve the oil production curve. Offshore Technology Conference, 2-5 May, Houston, 2005. https://doi.org/10.4043/17051-MS

Nwadike, N. G.; Ofia, I. J.; Essien, U. U.; Obong, B. U.; Amos, T.; Oton, E. U.; Adoghe, S. Enhancing the production performance of dual completed gaslifted wells using the Nova Venturi orifice valves. SPE Nigeria Annual International Conference \& Exhibition, Lagos, 5-7 August, Lagos, 2014.

Ribeiro, P. J. P.; Lima, F. S. Erosion speed effects on gas lift valves in well unloading operations. $\mathbf{3 2}^{\text {nd }}$ ASME/API/ISO Gas Lift Workshop, ASME/API/ISO, 2-6 February, The Hague, 2009 (available at www.alrdc.org ). 
Rilian, N. A.; Rohman, A. F.; Hamzah, K.; Arseto, Y. I.; Kurniawan, C. Successful application of Venturi orifice gas lift valve in Kaji-Semoga Field, South Sumatra: A case study. SPE Annual Technical Conference \& Exhibition, 5-10 October, San Antonio, 2012. https://doi.org/10.2118/159645-MS

Tokar, T.; Schmidt, Z.; Tuckness, C. New gas lift valve design stabilizes injection rates: Case studies. SPE Annual Technical Conference \& Exhibition, 6-9 October, Denver, 1996.

https://doi.org/10.2118/36597-MS 